\title{
Mitteilungen der Gesellschaft für Gastroenterologie in Nordrhein-Westfalen
}

Gastroenterologe 2015 $\cdot$ 10:527

DOI 10.1007/s11377-015-0022-z

() Springer-Verlag 2015

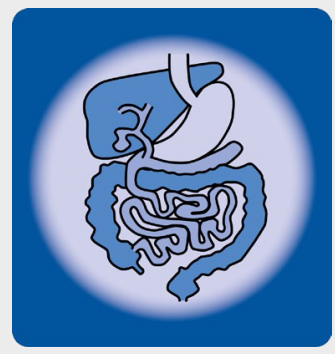

Gesellschaft für Gastroenterologie in Nordrhein-Westfalen

Schriftführer:

Prof. Dr. J.F. Erckenbrecht

Klinik für Innere Medizin mit Gastroenterologie und Onkologie,

Florence Nightingale Krankenhaus,

Kreuzbergstr. 79, 40489 Düsseldorf

Tel. 0211/4092500

Redaktion

C. Strassburg, Bonn

J. F. Erckenbrecht, Düsseldorf

\section{Nachruf Professor Dr. med. Burkard May}

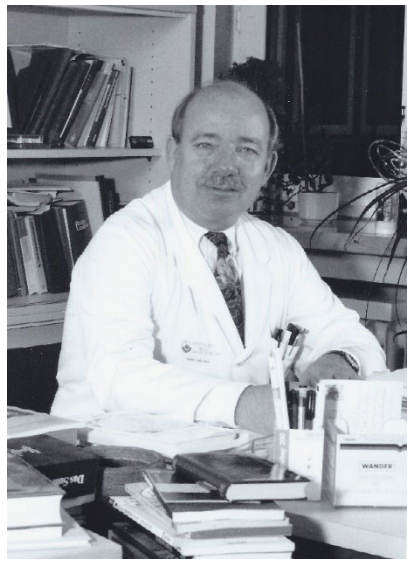

$\Delta$ Prof. Dr. med. Burkard May

Am 3.7.2015 verstarb Prof. Burkard May, von 1975-2002 Leiter der Abteilung für Gastroenterologie und Hepatologie der Medizinischen Klinik und Poliklinik am Universitätsklinikum Bergmannsheil in Bochum.

Geboren am 9.2.1936 in Köln und aufgewachsen in einem sehr kunstgeprägten Elternhaus, studierte May zunächst an der Hochschule für Musik in Freiburg/Br.

Er fühlte sich aber zum Arzt berufen und studierte Medizin in Freiburg, Köln, München und Marseille und promovierte in Freiburg über Herz-Kreislaufwirkungen von MAO-Hemmern.

Ab 1964 Assistent am Institut für Klinische Pharmakologie in Frankfurt/M bei Prof. P. Holtz. Ausbildung zum Internisten ab 1967 in Frankfurt/M bei Profs. W. Siede und W. Stille und ab 1969 an der Med. Hochschu- le Hannover (MHH) bei Prof. F. Hartmann und zum Gastroenterologen bei Prof. F. W. Schmidt. Habilitation 1971 zur Aufnahme, Speicherung und Freisetzung von Serotonin und Histamin in Thrombozyten.

Auf der Infektionsstation in Frankfurt hatte sich May mit dem Marburg-Virus infiziert. Am schlimmsten in seiner Erinnerung waren die Informationen im Fernsehen über den jeweiligen Tod der anderen Infizierten.

1975 übernahm May bei Prof. E. Fritze am „Bergmannsheil“ in Bochum den Auftrag, eine moderne Abt. für Gastroenterologie und Hepatologie aufzubauen. 1978 wurde Mays Abteilung eine Klinik der Ruhr-Universität Bochum. Wissenschaftliche Arbeitsschwerpunkte waren die Refluxkrankheit, Motilitätsstörungen, CED, Lebererkrankungen, GI-Tumore, Suchtkrankheiten und die Schmerztherapie. Seltene Krankheiten weckten regelmäßig sein Interesse, z. B. das Köhlmeier-Debos Syndrom.

Mays 150 Publikationen als Erstautor oder Initiator umfassen aber auch Untersuchungen zu komplizierten Stoffwechselwegen und Nachweismethoden von Medikamenten und körpereigenen Substanzen.

May war aber nicht nur Forscher, sondern auch engagierter Mitgestalter der Entwicklung der Inneren Medizin und der Gastroenterologie in Nordrhein-Westfalen.
1991 war May Gründungsmitglied und 1994/95 Präsident der Gesellschaft für Gastroenterologie in NRW, 1992 war er der 1. Vorsitzende der Rheinisch-Westfälischen Gesellschaft für Innere Medizin (RWGIM) und später Ehrenmitglied. Als Gründungsmitglied und erster Vorsitzender gehörte er der Ethikkommission der Ruhr-Universität Bochum (RUB) an. Die Landesregierung hatte ihm die wissenschaftliche Leitung des Projektes „Methadonsubstitution von Drogenabhängigen “ übertragen. May legte hier die Basis für die heutige Therapie. Er war langjährig im Beirat der Medica und der DCCV. 2006 wurde er mit der höchsten Auszeichnung des Berufsverbandes Deutscher Internisten (BDI), der Günther-Budelmann Medaille geehrt.

In seiner Klinik und ebenso als Kongressleiter im In- und Ausland veranstaltete May regelmäßig Endoskopiekurse und überregional beachtete Seminare mit namhaften Experten zu aktuellen gastroenterologischen Themen. Aus Mays Klinik gingen 4 Professoren, 50 Promotionen und 12 Chefärzte/innen in angesehenen Kliniken hervor.

May war Autor und Mitherausgeber des Standardwerks für sozialrechtliche Institutionen „Die ärztlichen Begutachtung“ von Eugen Fritze und einer detaillierten Geschichte der Inneren Medizin von 1903 bis 2003 in Nordrhein-Westfalen. May war Gutachter bei der ÄK Westfalen-Lippe und bis zu seinem Lebensende bei der Berufsgenossenschaft und der Architektenkammer.

Seine Mitarbeiter erinnern sich an einen scharfsinnigen und fleißigen Chef, seine Direktheit, natürliche Autorität und seinen feinen, ansteckenden und oft medizinisch gefärbten Humor. May war fast bis zum Lebensende von robuster Gesundheit. Sein Kommentar: Wer die "Affenseuche“ (Marburg Virus) überlebt, wird nicht mehr krank.

May war Mediziner, Arzt und Humanist „durch und durch". Seine Hobbies: Literatur, Geschichtswissenschaft, Musik, Theater und Oper. Der Freundeskreis der Bochumer Symphoniker wählte ihn zu seinem Vorsitzenden.

Wir trauern mit seiner Familie um einen hochgeschätzten Freund und Kollegen, den wir in dankbarer Erinnerung behalten werden.

Prof. Dr. Jürgen G. Freise für seine Freunde, Mitarbeiter und die Ges. f. Gastroenterologie in NRW. 